\section{Manutenção e Gestão do Dador de Órgão na Era} COVID-19

\section{Management of Organ Donation During the COVID-19 Pandemic}

Palavras-chave: COVID-19; Infecções por Coronavírus; Obtenção de Tecidos e Órgãos; Pandemia; SARS-CoV-2; Transplante de Orgãos

Keywords: Coronavirus Infections; COVID-19; Organ Transplantation; Pandemics; SARS-CoV-2; Tissue and Organ Procurement

\section{Caro Editor,}

O impacto da pandemia de COVID-19 na transplantação era expectável, receando-se uma redução substancial do número de transplantes realizados em Portugal, à semelhança do cenário catastrófico que se verificou em países como Espanha e Itália. ${ }^{1}$

No entanto, ao fazermos uma análise retrospetiva do número de dadores de órgão no nosso serviço de Medicina Intensiva, verificámos que, nos primeiros nove meses de 2020, não se constatou uma diminuição do número de dadores relativamente a períodos homólogos dos últimos cinco anos. Contamos, desde 1 de janeiro de 2020 e até à data de elaboração desta carta, com sete dadores efetivos falecidos em morte cerebral.

Durante este período, têm sido vários os desafios com que nos temos confrontado para uma adequada manutenção e gestão do dador de órgão falecido em morte cerebral, que aqui expomos aos restantes colegas e trazemos a discussão.

Previamente à admissão na unidade de Cuidados Intensivos (UCI), todos os doentes têm de ter pelo menos um rastreio de SARS-CoV-2 negativo. Os testes rápidos de rastreio permitiram acelerar bastante este processo, e têm sido atualmente utilizados nestes casos, assumindo-se as presumíveis vantagens de uma rápida admissão na $\mathrm{UCI}$, ainda que seja necessária uma utilização bastante criteriosa destes testes, cuja disponibilidade é limitada.

Após a admissão na $\mathrm{UCI}$, procuramos que o tempo de manutenção do potencial dador seja o menor possível, de forma a preservar a viabilidade dos órgãos. ${ }^{2}$ No entanto, mesmo em condições ideais, este processo tem sido atrasado pela necessidade de realização de mais um teste de rastreio de SARS-CoV-2, cujo resultado pode demorar até 12 horas.

Quando reunidas as condições para a realização das primeiras provas de morte cerebral, e se o segundo teste de rastreio de SARS-CoV-2 estiver ainda em curso, efetuamos a prova de apneia em circuito fechado, sob CPAP, ${ }^{3}$ ainda que tradicionalmente (numa era pré-COVID-19) esta prova se fizesse através da desconexão do ventilador.

A demora média de internamento dos potenciais dadores de órgão admitidos na nossa $\mathrm{UCl}$ nos primeiros nove meses de 2020 foi de 4,5 dias, comparativamente a uma média de 3,6 dias nos períodos homólogos dos cinco anos precedentes, confirmando assim uma maior demora, provavelmente associada à necessidade de realização dos testes de rastreio de SARS-CoV-2, mas que é fundamental para minimizar o risco de infeção dos doentes transplantados.

A proteção do potencial dador de órgão da infeção pelo SARS-CoV-2 deve ser também assegurada, não podendo em momento algum ser descurada, tanto durante o contacto com os profissionais de saúde, como aquando do momento de despedida dos familiares. Este processo, já emocionalmente difícil, torna-se ainda mais complicado de gerir na atual situação pandémica. Apesar da restrição de visitas aos doentes no nosso hospital, estas têm sido permitidas em situações excepcionais, desde que com a adequada utilização de equipamento de proteção individual. O contacto das equipas médica e de enfermagem com os familiares tem sido também, sempre que possível, realizado presencialmente, por constituir um aspecto importante no processo de luto que não deve ser desvalorizado. ${ }^{4}$

Esperamos que os processos e dificuldades aqui mencionados possam ser fonte de discussão entre a comunidade médica, com vista a uma optimização da manutenção e gestão do dador de órgão falecido em morte cerebral em plena pandemia COVID-19.

\title{
REFERÊNCIAS
}

1. Loupy A, Aubert O, Reese P, Bastien O, Bayer F, Jacquelinet C. Organ procurement and transplantation during the COVID-19 pandemic. Lancet. 2020;395:e95-6.

2. Chamorro-Jambrina C, Muñoz-Ramírez M, Martínez-Melgar J, PérezCornejo M. Organ donor management: eight common recommendations and actions that deserve reflection. Med Intensiva. 2017;41:559-68.

3. Greer D, Shemie S, Lewis A, Torrance S, Varelas P, Goldenberg F, et

al. Determination of brain death/death by neurologic criteria: The World Brain Death Project. JAMA. 2020;324:1078-97.

4. Pearson I, Bazeley P, Spencer-Plane T, Chapman J, Robertson P. A survey of families of brain dead patients: their experiences, attitudes to organ donation and transplantation. Anaesth Intensive Care. 1995;23:88-95

Sofia Branco RIBEIRO $\rrbracket^{1}$, Miguel VARELA', Pilar PEREZ¹, Javier MORENO1

1. Serviço de Medicina Intensiva. Hospital de Faro. Centro Hospitalar Universitário do Algarve. Faro. Portugal.

Autor correspondente: Sofia Branco Ribeiro. apribeiro@chalgarve.min-saude.pt

Recebido: 21 de setembro de 2020 - Aceite: 22 de setembro de 2020 | Copyright $\odot$ Ordem dos Médicos 2021

https://doi.org/10.20344/amp.14958

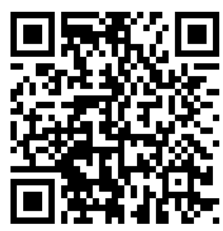

